OUTROS ESTUDOS 


\title{
DEUSDEDIT, JOAKIM, SEUS LIVROS E AUTORES
}

\author{
Cláudio DeNipoti ${ }^{*}$
}

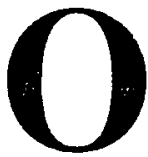

$s$ diversos caminhos que a pesquisa histórica assume em seu decorrer são provavelmente seu aspecto mais encantador. É sem dúvida notável a perseverança que atém algumas centenas de pessoas razoavelmente sérias e, em alguns casos, extremamente inteligentes e ilustradas, horas a fio em arquivos e bibliotecas, sofrendo todo o tipo de incômodo ao lidar com objetos e papéis - mais freqüentemente - velhos e empocirados.

Todos eles discordariam veementemente do jornalista anônimo curitibano que, em 1911, criticava a então Biblioteca Pública do Paraná em termos nada elogiosos, dizendo que

[...] a nossa [biblioteca], sempre emperrada nos montōes de livros de venerável antigüidade, alli está n'uma acunhada sala do Gymnasio, fossilisada em archaicos armários, sob camadas de pó e mais própria a tentar a curiosidade de algum archeólogo do que a do estudioso dominado pelo justo receio de infecção pelos bacillos de Koch que ali socegadamente proliferam confiados na desidia do Estado.'

* Universidade Estadual de Londrina

1 BIBLIOTHECA PÚBLICA. O Parana, Coritiba, v. 2, n. 47, p. 1, 24 abr. 1911. 
Ao contrário, vários historiadores estariam dispostos - hoje e naqueles dias - a correr o risco de contágio, unicamente para encontrarem "fontes" para seu trabalho de escrever a história. Robert Darnton conforta o historiador quando afirma que "construir mundos é uma das tarefas essenciais do historiador, e ele não a empreende pelo estranho desejo de escarafunchar arquivos e farejar papel cmbolorado - mas para conversar com os mortos". ${ }^{2}$ É um conforto relativo, porém, pois à gratificante tarefa de (re)construir mundos ainda se opõem as diliculdades que o historiador - de qualquer tendência teórico-metodológica enfrenta $a^{3}$ no intuito de ver concluídas suas considerações sobre, digamos, a cultura sexual greco-romana, a Paris de Voltaire ou o universo político da 1. República no Brasil.

É claro que, depois que reúne seu material de pesquisa e começa a refletir sobre ele - ou melhor, a refletir com ele - o historiador pode sentir-se menos incomodado fisicamente e buscar aquela reconstrução de mundos perdidos com uma maior liberdade.

A Biblioteca Pública do Paraná pode servir para ilustrar essa série de relações que a pesquisa assume em seu percurso, por vezes partindo para caminhos que o historiador sequer imaginava poderem ser trilhados.

O trabalho com os registros de retirada da Biblioteca Pública do Paraná (BPPR) pode ser descrito dentro do quadro desenhado no início deste texto. As quase duas dezenas de livros-ata empoeirados, roídos por traças, incompletos, jogados de um canto a outro da atual Biblioteca Pública do Paraná, conforme as necessidades de espaço e as múltiplas reformas e rearranjos - verdadeiro motivo de pânico para qualquer pesquisador - fornecem, contudo, um material extremamente rico, ainda que talvez seja somente a faísca inicial para um trabalho mais completo. ${ }^{4}$

Esses registros são instigantes para a pesquisa, ainda que, em si sós, não constituam um objeto - ao menos não um objeto completo - de uma história da leitura, já que fornecem panoramas gerais sobre a leitura no passado (quem lia o quê, quando e quanto) e não entram nas questões mais específicas da relação cognitiva implícita no ato de ler. Esses panoramas são, contudo, absolutamente necessários para apoiar essas últimas questões. ${ }^{5}$

2 DARNTON, Robert. Bốmia literária e revolução: o submundo das letras no Antigo Regime. São Paulo: Companhia das Letras, 1987. p. 7.

3 Talvez o termo inglês endure, significando aturar, agiientar, ao mesmo tempo que perseverar e persistir, dê uma idéia melhor dessa tarefa.

4 DeNIPOTI, Cláudio. Páginas de prazer: a sexualidade através da leitura no início do século. Curitiba. 1994. Tese de Mestrado (História) - UFPR.

5 ld. Leitores, escritores e o casamento. Boletim do Departamento de História da UFPR, Curitiba, n. 31, p. 33-48, 1994. 
É sobre esse panorama geral - ou um panorama possível - que gostaria de deter-me um pouco. Naturalmente, para não reproduzir aqui os próprios registros em sua íntegra (como o mapa perfeito de Borges), ${ }^{6}$ tomo o universo das leituras de dois assíduos frequientadores da BPPR. Ainda que no atual estágio da pesquisa faltem maiores informações sobre esses dois personagens, desde o início eles causaram espécie ao pesquisador, seja pelo estranho nome de um deles - Deusdedit -, seja porque eles eram irmãos, seja ainda pela diversidade e freqüencia de suas leituras. Deusdedit e Joakim Moura Brasil também suscitaram questões sobre os hábitos da leitura no passado que gostaria de tentar desenvolver aqui e, no final, cruzar os escritos (fundamentais para esta análise) que os leitores Deusdedit e Joakim deixaram, com suas leituras na BPPR.

Este estudo preliminar, colocado portanto como um panorama geral da leitura no início do século, embora seja inicialmente marcado por uma abordagem quantitativa, não pretende situar a história da leitura no âmbito da Histoire sericlle cal troisième niveall, de Pierre Chaunu "(o 'terceiro nível', após o econômico e o social sendo aquele da cultura)". "Essa abordagem, dominante na historiografia francesa durante os anos 70 , é caracterizada como a tentativa de "medir comportamentos através da contagem - contando missas para os mortos, quadros mostrando o purgatório, lítulos de livros, discursos em academias, móveis em inventários, crimes nos arquivos policiais, invocações à Virgem Maria em testamentos, e o peso da cera das velas queimadas para os santos patronos das igrejas". 8 Robert Darnton objeta a essa abordagem afirmando que, em primeiro lugar, os objetos culturais, por não serem fabricados pelo historiador, mas sim pelas pessoas que ele estuda, têm uma natureza diferente daquela das informações contidas nas séries das histórias econômical e demográfica. "Eles têm que ser lidos, e não contados." Em segundo lugar, "a cultura não pode ser considerada como um nível de alguma entidade social semelhante a uma casa de três andares porque todas as relações interpessoais são de uma natureza cultural, mesmo aquelas que qualificamos de 'econômicas' ou 'sociais'."'

Sendo assim, esse estudo quer simplesmente, lançando mão do material bruto fornecido pela pesquisa naqueles papéis empoeirados dos livros de registro de retirada, pensar a partir do que esses registros fornecem. Ainda que antes de

6 BORGES, Jorge Luis. A biblioteca de Babel. In: Fiçõer. São Paulo: Abril Cultural, 1971, p. 84-94. n. 4, Dec. 198.5 .

7 CHARTIER, Roger. Text, symbols and frenchuess. Joumul of Modern History, v. 57 ,

8 DARNTON, Robert. O grande massacte de gatos e outms episódios da história cultural francesa. Rio de Janeiro: Graal, 1986. p. 330.

9) CHARTIER. Text...; DARNTON, O grande massacre..., p. 330-331. 
1952 a BPPR tenha sido mais uma intenção do que um fato, ela existiu desde meades do século XIX na forma de uma pequena sala de livros, funcionando em salas cedidas por diversos órgãos do governo do Estado, principalmente o Givmnasio Paranciense. Nas décadas iniciais deste século, as descrições da BPPR são as de um órgão estatal abandonado pelo governo e razoavelmente restrito a um público de estudantes do Gymnasio. ${ }^{\text {t( }}$

Os registros de retirada, marcados cotidianamente pelos bibliotecários c/ou responsáveis pela BPPR que se sucederam nos anos para os quais os livros ainda existem. fornecem uma série de idéias sobre a leitura no passado. Deusledil e Joakim surgem nos registros pela primcira vez em 1914 (este cm fevereiro a aqucle em março). Ambos freqüentam a biblioteca intermitentemente até 1917, culando Joakim desaparece dos registros. Deusdedit continua retirando livros até outubro de 1918. Nesse ponto há uma interrupção nos registros remancscentes até 1921. Nenhum deles reaparece nos registros entre essa data c 19.37. Durante os anos em que ambos freqüentam a BPPR, é grande o número de dias em que os dois são listados consultando as obras do acervo.

As listagens claboradas a partir de seus registros de leitura mostram uma ampla gamat de interesses e uma intensa troca de informações sobre as obras lidas. É comum que, em curtos espaços de tempo, ambos consultem o mesmo livro. indicando que o primeiro leitor pode ter intluenciado as escolhas do segundo. É o calso, por exemplo, das Cartas literárias, de Adolpho Caminha, consultadas por Joakim em 5 de fevereiro de 1917 e por Deusdedit dois dias depois. Ou ainda Casa de pensãa, de Aluizio Azevedo, que Deusdedit lê durante outubro de 1914 (três consultas nos dias 6,15 e 19, indicando renovação de empréstimo) e que Joakim lê no mês seguinte (dias 9 e 12 de novembro), 0 mesmo acontecendo nesses mesmos meses (porém com dias diferentes nos registros) com outro livro de Azevedo, $O$ cortija. (ver tab. 1)

Ao lodo eles estiveram na BPPR em 373 dias entre 1914 e 1918 (em 116 desses cliats, ou cerca de 32\%, ambos foram à biblioteca, possivelmente juntos). Seus nomes loram anotados nos livros de retirada mais de 550 vezes nesse período. relierentes a 137 títulos de obras para Deusdedit e 78 para Joakim."

10 BIBLIOTHECA PÚBLICA. O Paramí. Coritiba, v. 6. n. 47. Curitiba, 24 abr. 1911; A Nossa hibliotheca. (iarcu do Pow, Coritiba, p. 1, 26 ago. 1920. Ver também DeNIPOTI. l'isimas.... p. 22-24. $160-167$.

11 Para lins de comparação (e também buscando demonstrar a representatividade dos dados relativos ans nossus personagens), o total de consultas feitas à BPPR durante o periodo 191.-1918 foi de 6.939. Deusdedit e Joakim contribuem portanto com 7,9\% desse total, sendo este um dos maiores percentuais de consultas entre os freqüentadores da BPPR. 
Tabela 1 - Lcituras dos Moura Brasil na BPPR em outubro e novembro de 1914

\begin{tabular}{|c|c|}
\hline \multicolumn{2}{|l|}{ Data } \\
\hline $01 / 10 / 14$ & Deusdedit \\
\hline 011 & 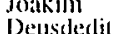 \\
\hline 021 & Deusdedit \\
\hline $02 /$ & Joikim \\
\hline $03 /$ & Joakin \\
\hline $03 /$ & Deusdedit \\
\hline (0.5/ & Deusdedit \\
\hline (1)6! & Deusdedil \\
\hline $06 /$ & Joakim \\
\hline $08 /$ & Deusdedil \\
\hline $10 \%$ & Deusdedit \\
\hline $10 /$ & Joakim \\
\hline $1.3 /$ & Detusdedit \\
\hline 141 & Deusdedit \\
\hline 141 & Joakim \\
\hline $1.5 /$ & Joikim \\
\hline $1.5 /$ & Deuscledit \\
\hline 161 & Deusdedit \\
\hline $16 /$ & Joakim \\
\hline $19 /$ & Deusdedit \\
\hline 191 & Joakim \\
\hline 2()$/$ & Deusdedit \\
\hline $23 /$ & Deuscledit \\
\hline $24 /$ & Deusdedit \\
\hline $24 /$ & Joikim \\
\hline 271 & Deusdedit \\
\hline $27 /$ & Deusdedit \\
\hline $28 /$ & Deusdedit \\
\hline $28 /$ & Joakim \\
\hline 3()$/$ & Deusdedit \\
\hline (0)3/11/14 & Joakim \\
\hline $03 /$ & Deusdedit \\
\hline (1)4! & Deusdedit \\
\hline $04 /$ & Deusdedit \\
\hline $05 /$ & Joakim \\
\hline $0.5 /$ & Joakim \\
\hline $06 /$ & Deusdedit \\
\hline $07 /$ & Deusdedit \\
\hline (09) & Joakim \\
\hline $09 \%$ & Deusdedit \\
\hline$\cdot 10 /$ & Deusdedit \\
\hline $10 /$ & Jonkim \\
\hline 111 & Deusdedit \\
\hline $12 /$ & Deusdedit \\
\hline $12 /$ & Joukim \\
\hline $1.3 /$ & Deusdedit \\
\hline $13 /$ & Ioakin \\
\hline 161 & Deusdedit \\
\hline 161 & Joakim \\
\hline 171 & Detusdedit \\
\hline 20$)$ & Deusdedit \\
\hline 2()$/$ & Joakim \\
\hline $2.3 /$ & Deusdedit \\
\hline $23 /$ & Joakim \\
\hline 241 & Deusdedit \\
\hline $24 J$ & Joakim \\
\hline $2.5 /$ & Deusdedit \\
\hline $25 /$ & Jonkin \\
\hline 26$)$ & Deusdedit \\
\hline $26 \%$ & Joakim \\
\hline $27 /$ & Deuscledit \\
\hline $27 !$ & Joakim \\
\hline $3(1) /$ & Deusdedi \\
\hline
\end{tabular}

Título da obra

História Universal

Culto Do Dever (O)

Recreaçīo Philosophica

História Natural

Theatro

Theatro

Metnórias Do Sobrinho De Meu Tio

História Universal

Casa de Pensĩo

Recreação Philosophica

História Natural

História Do Brasil

Theatro

História Natural

História Universal

Theatro

Memórias Do Sobrinho De Meu Tio

Casi De Pensão

Recreaçāo Philosophica

Meinórins Do Sobrinho De Meu Tio

Casa De Pensão

História Do Brasil

História Universal

Recreaçĩo Philosophica

Coruja (O)

Liçoes De História

História Universal

Mulheres Celebres

Coruja (O)

Hygiene Do Amor

Coruja (O)

Hygiene Do Amor

Recreação Philosophica

Coruja (O)

História Universal

História Universal

Hygiene Do Aunor

Coruja (O)

História Universal

Cása De Pensão

Physica

Recreação Philosophical

Mba

História Universal

História Natural

Casa De Pensĩo

Romanceiro (O)

Coruja (O)

Recreação Philosophica

Coruja (O)

História Universal

História Universal

Coruja (O)

Recreação Philosophica

Coruja (O)

História Natural

Forasteiro (O)

Romanceiro (O)

Forasteiro (O)

História Do Brasil

Forasteiro (O)

História Universal

Cortiço (O)

História Universal
Autor

Botelho, Raposo

Macedo, Manoel De

Almeida

Langlebert, J.

Macedo, Manoel De

Macedo, Manoel De

Macedo, Manoel De

Botelho, Raposo

Azevedo, Aluizio De

Almeida

Langlebert, J.

Ribeiro, Joño

Macedo, Manoel De

Langlebert, J.

Botelho. Raposo

Macedo, Manoel De

Macedo, Manoel De

Azevedo, Aluizio De

Almeida

Macedo. Manoel De

Azevedo. Aluizio De

Pombo. Ruclia

Botelho, Raposo

Almeidia

Azevedo, Aluizio De

Vellozo, Dario

Anquetil

Macedo, Manoel De

Azevedo, Aluizio De

Mantegazza, Paolo

Azevedo, Aluizio De

Mantegazza, Paolo

Almeida

Azevedo, Aluizio De

Botelho. Raposo

Anquetil

Mantegizza, Paolo

Azevedo. Aluizio De

Botelho, Raposo

Azevedo, Aluizio De

Guedes

Almeidia

Munhoz, Alcides

Botello. Raposo

Langlebert, J.

Azevedo. Áluizio De

Coelho Netto

Azevedo. Aluizio De

Almeida

Azevedo, Aluizio De

Botelho, Raposo

Anquetil

Azevedo, Aluizio De

Almeida

Azevedo. Aluizio De Langlebert, J.

Macedo, Manoel De Macedo. Manoel De Macedo, Manoel De

Ribeiro. Joño

Macedo, Manoel De

Anquetil

Azevedo, Aluizio De

Botelho, Raposo 
Dessas obras, ambos consultaram, em um ou outro momento, 38 títulos, que incluem, entre outros, diversas obras de Manuel de Macedo, José de Alencar e Aluizio Azevedo, Antropologia e Raças humanas de Oliveira Martins, Os sertĩes de Euclides da Cunha e Literatura contemporânea de Sílvio Romero. (ver tab. 2)

Tabela 2 - Leituras dos Moura Brasil na BPPR 1911-1918- Leituras coincidentes

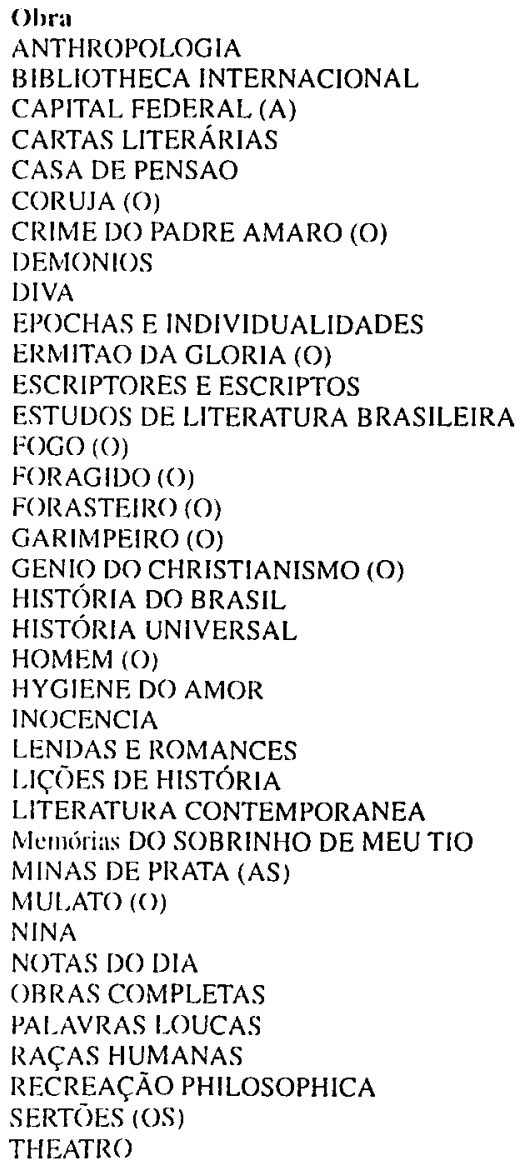

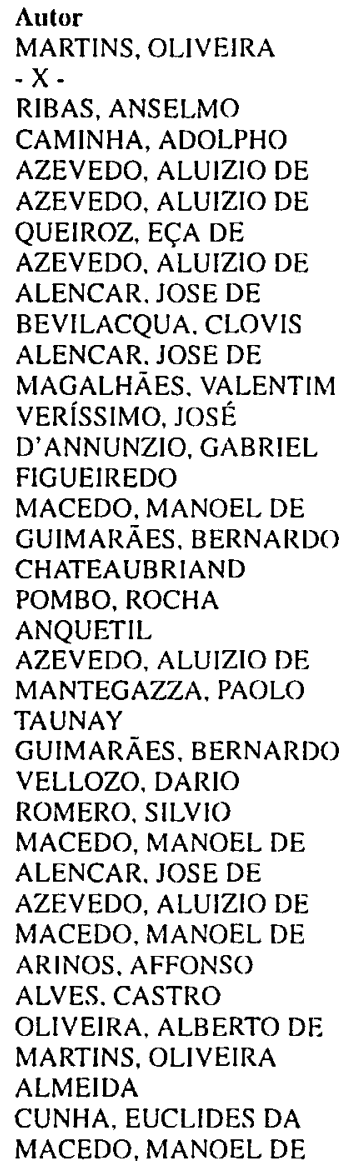


Os registros de leitura permitem um mapeamento quantitativo, portanto, das leituras realizadas pelos irmãos Moura Brasil. Porém, no universo da história da leitura, as constatações estabelecidas por números com relação ao que foi lido, quando e por quem não são suficientes. É necessário ir além e buscar as razões e as formas da leitura no passado.

Como podemos fazer isto no caso de nossos dois leitores? Primeiramente, é necessário que estabeleçamos melhor quem eles foram, qual seu passado com relação ao momento estudado e o que fizeram a partir de então. Em segundo lugar, devemos buscar em seus escritos as pistas sobre suas leituras, que de outra forma seriam inacessíveis para o historiador de hoje.

Nascidos no final do século XIX (Deusdedit em 1897 e Joakim em 1899), no interior do Ceará, os Moura Brasil vêm para o Paraná cm 1909, por iniciativa de scu pai, seleiro - "como o pae de Kant" - que viajava pela regiāo Norte do Brasil vendendo seus produtos. Segundo o julgamento do chefe da família, o Sul, além de possibilitar melhores oportunidades de trabalho, também proporcionava "grande probabilidade de instruir os filhos, de formal-os homens úteis - e nos citava, frio mas sincero, patrícios nossos, no sul, econômica e intelectualmente preponderantes". 12

Inicialmente vivendo em Morretes, a família dedica-se à agricultura, e os fïlhos têm que participar do trabalho junto com seu pai. Sobre esse período de trabalho duro, Deusdedit diz que nenhum dos dois irmãos sentiu-se degradado por ter que trabalhar a terra, pois eles aprenderam "num livro de leitura infantil [que] o imperador chinez em certa phase do anno, empunhava o arado para mostrar aos suditos quão dignificante o labor agrícola". 13 Em Morretes também, Joakim dá as primeiras mostras de gênio artístico e intelectual, dedicando-se ao desenho e à pintura desde tenra idade, pois "tendo ás mãos uma estampa lytographica, reclamo, copiava-a com gosto, reproduzindo também, com interesse, caricaturas de revistas, que lhe chegavam ao alcance". ${ }^{14} \mathrm{Em} 1910$, Joakim redige um semanário manuscrito que quase causa a prisão de seu pai, devido à suspcita que fosse ele, e não o filho, o autor de artigos contra o Gremio Hortus Morretense. "O delegado, senhor Arthur Balster, não duvidava o auctor do escripto fosse papae, que só depois de ver o nome de seu filho no jornaleco soube da vocação jornalística do mano que tão pequeno revolucionava a cidade com seu arremedo de jornal em linguagem toda assimilada do terrível jornalista

12 MOURA BRASIL, Deusdedit. Ensaio biographico sobre J. H. Moura Brasil, n. 1.899. f. 1.917. Revistu Acudêmica, Coritiba, v. 2, n. 7, p. 182-183, jul. 1918.

13 Id., Ensaio biographico..., Revista Acadêmica, Coritiba, v. 2, n. 8, p. 211, cont. 214 , ago. 1918.

14 Ibid. 
cearence João Brigido, incomprehensivel político que papae admirava e por isso guardava uma colleç̧ão do Unitario fonte encyclopedica do saudoso mano, que entio tinha dez anos de idade."15

Ainda segundo Deusdedil, nessa ćpoca seu irmão já demonstrava uma forle ubsessão pela morle, que the adviria prematuramente em 1917 (explicando assim o lim de sulas visitas à BPPR em março daquele ano). ${ }^{16}$ Em um artigo de 1916. parte de um de seus livros inéditos (Dentro da vida), essa obsessão se manilesta nas inquielações de um enfermo:

Tentou levantar-se, mas a sua geral fraqueza negou-lhe o esforço requerido para se por de pé... Tal era a sua debilidade physical, que nem siquer um membro conseguiu animar; parecia que seu corpo todo, n'uma contração maciabra c vil, estava privado da laculdade de locomoçăo; dir-se-ia que uma forle lethargia paralysara-Ihe os movimentos os mais futcis...

Profundo desespero invadiu-lhe a alma, em convulsões de dor... diante de tanta resistência a que senão podial oppor, tal o depautperamento de suas forças, elle se maldisse, n'acpuella hora em que seu coração não podia render um preito amigo de gratidão aos pés da donzella bemfazeja...

Era profundo o scu pezar c mais a sua inquietação, a agitar-lhe as fibras, como vagalhōes frementes de mar encipellado, a se chocarem d'encontro alos cachopos musgosos...

Devemos supor que os irmãos vieram para Curitiba por volta de 1914 para realizar o desejo de seu pai de que se instruíssem. É nesse ano que seus nomes começam a aparecer nos registros de retirada, levando-nos a crer que, ¿omo a glande maioria dos freqüentadores da BPPR, eles fossem alunos do Gymmession Paremaense, que abrigava o acervo da biblioteca. De fato, no ano seguinte. Deusdedit aparece como aluno do primeiro ano do curso de "Sciencias Juridicats e Sociaes" da Universidade do Paraná. em seu terceiro ano de fun-

15 MOURA BRASIL. Deusdedit. Ensaio biographico.... p. 213.

16. Deusdedit publicia um ensaio biográfico sobre seu irmĩo em virios capitulos. Lamenlavelmente as tiltimas partes do ensaio deixaram de ser publicadas por algum motivo, e nĩo pudemos salber a caltsal ou a data precisa da monte de Joakim.

17 MOURA BRASIL, Joakim Honorio. O enfermo (Capitulo LXXI do livro inédito Demto da vikla). A falua. Coritiba, v. 1, n. 1, p. 7-9. 1 ago. 1916. 
cionamento. ${ }^{18}$ Embora não exista referência a Joakim nas listagens de alunos da Universidade, supomos que ele passou os anos de 1914 a 1917 estudando em Curitiba, compartilhando com seu irmão as leituras que ambos realizaram na sala de leitura da Biblioteca Pública ou aquelas que Deusdedit possa ter feito na bibliotecia da Universidade entre 1915 e o ano da morte de seu irmão. Após formar-se advogado, Deusdedit prestou concurso para "Iente substituto" na faculdade que cursara, em 1920. Não foi possível descobrir se sua tese foi ou não aprovada, mas ele a publicou no mesmo ano pela Empreza Graphica Parcinaense."

No tocante aos escritos de nossos dois personagens, pouco daquilo que Joakim escreveu chega a ser publicado. Além do artigo "O enfermo", citado acima, há também um trecho de seu oitavo romance, ainda inédito, $O$ rato branco, "concepção dos quinze anos incompletos", terminado em fevereiro de 1914, um texto ufanístico do sertão paranaense, escrito com algum esmero literário e assinado sob o pseudônimo Sursum Corda, que seu irmão inclui no longo necrológio que publica em capítulos em $1917 .^{20}$

Já Deusdedit teve vários de seus trabalhos publicados, além da referida tese de concurso Ontogenia do Direito Commercial, de 1920, ele publicou Loiras ao sol, sobre a seca em seu estado natal, e um discurso proferido em 1922 na região oeste do Paraná. ${ }^{21}$ Em 1925, ele publicou, juntamente com sua esposa Aldamira, um pequeno livro de sonetos dedicados a Jesus, à Mãe Santíssima c a diversos santos católicos, mais como orações em verso que qualquer outra coisa. ${ }^{22}$ Há, além disso, a referência a obras que permaneceram inéditas, como os romances Os filhos do tropeiro e Alma de garoto $^{2.3}$ e as obras jurídicas $A$ criminalidade no Paraná e Estrea no Fôro.

I8 RELATÓRIO Geral da Universidade do Paraná para 1915. Curityba: Typographia Max Rocsner: 1915: RELATÓRIO Gẹal da Universidade do Parani para 1916. Curityba: Tylographiai d'A República. 1917.

19) MOURA BRASIL, Deusdedit. Ontogenia do direito commercial: dissertaçĩo e theses de concurso para prehenchimento do cargo de lente substituto [...] da Faculdade de Direito do Paraná. Coritiba: Empreza Graphica Paranaense, 1920.

20) Il.. Ensaio biographico..., Revista Acadêmica, Coritiba, v. 2. n. 6. p. 154-1.56, jun. 1918.

21 Il., Loiras ao sosl: acerca da seca no Ceará. Curitiba: Livraria Mundial, 1919; Na fromleira do Brasil rom a Argentina e o Paraguai. Curityba: Typographia Moderna, 1922. Apud MOREIRA, Julio Estrella. Dicionario biblingrifico do Paranci. Curitiba: Imprensa Oficial do Estado. 1957.

22 MOURA BRASIL, Aldamira; MOURA BRASIL, Deusdedit. Maria Salomé: sonetos. Coritiba: Moderna, 1925.

2.3 MOURA BRASIL, Deusdedit. Ensaio biographico..., Revista Acadêmica, Coritiba. v. 2. 1. 7, p. 182-184, jul. 1918. 
Leitor assíduo, Deusdedit deixa em seus escritos inúmeras impressões, não somentc sobre os autores e obras que leu, mas também sobre o próprio processo de aprendizado calcado na leitura e sobre os meios para este aprendizado. Em sua dissertação para o concurso de professor na Faculdade de Direito, Deusdedit descreve de forma bastante enfática o processo que caracterizou sua passagem pelas salas de aula daquela mesma faculdade. Esta foi, para ele, uma "phase acerrima em que me trepidaram espírito e corpo, como arbustos transplantados a regiōes estranhas a lutarem com o meio tellurico..."

Este processo foi traumático, já que não buscava meramente obter as notas para a aprovação nas cadeiras que cursou, mas tentava dar conta do aprendizado de forma mais completa. O trauma se manifesta ante o volume de lcituras que ele teria que fazer durante e após seu curso, expresso como "pasmo e deslumbramento causados pela obra humana, contemplada no espelho prefulgente da bibliografia inexgotável que senti vontade absurda de resumil-a em fóco e aluminar-me de vez, como por processo mechanico se desaggrega, se deslia, sem aç̧ão do tempo e da lucta, o corpo em cinzas ou em pó".

Assim, Deusdedit sofreu com a diversidade de escolas, doutrinas e teorias, com a versatilidade dos conceitos, argüições e postulados, tanto $\mathrm{em}$ direito quanto em sociologia, religião e literatura. Sofrimento descrito sem meias palavras, pois elc recebeu "pelas ilhargas acicates da controvérsia, ferrões de mil tayocas, supplicio de dezenas de serras, torquazes e alfinetes - escolas sobre escolas, theorias sobre theorias, verdades misturadas com embustes, sciencia calma e branda com phantasia apaixonada, crença com lógica, mytho com realidade". 25 Seu solrimento foi ainda pior por não lançar mão de estimulantes que facilitissem sua compreensão de seu material de leitura, pois "soffrer sem buscar no absyntho ou alcool, alívio á sensibilidade, é soffrer duplamente", pois atirar-se solitário à tarefa de iniciar-se na cpopéia do pensamento sem a "inconsciencia, automatismo e desleixo" provocados pelo absinto é tão penoso quanto "arrastar onerosa canga de capricho, de independência, de não aceitar e acolher a primeira idéia çue se antolha, circumloqua, vasia, archaica, brunida e exornada pelo oiropel literário". 26

Não obstante, sua busca ia para além do conhecimento superficial sobre os assuntos de seu interesse, para "regiões mais altas" e "recantos mais límpidos", as razões últimas que lhe proporcionassem a satisfação de viver em paz,

24 MOURA BRASIL. Deusdedit. Ontogenia..., p. 7.

25 Ibid.. p. 7.

26 Ibid.. p. 7. 
reservado e imune. A satisfação de "lançar olhar em torno de si e não ignorar demasiadamente". 27 Buscava poder discernir entre "a semente e a casca", habiluar-se a "colher do emaranhado venenoso [...] a jóia ou o brinco que deleitará e confortará o espírito em seguida". 28

Após esse processo, Deusdedit avalia que está capacitado para excrcer o cargo de professor substituto porque amadureceu o suficiente, ou, $\mathrm{cm}$ suas palaıras:

Estou na phase do incubo, do empollamento, ou melhor, na puberdade mental, satisfeito porque esclareci ao meu espírito irriquieto as primeiras duvidas, distendi-lhe a primeira māo de cal, dei-lhe a primeira luz, retirei-o dos cachos da escuridade, iniciei o grande enigma, c agora, poderá adejar ao talante sem ignorância pasmosa de quem contempla herbario, sem fazer antecipadamente classificação de cada arbusto. ${ }^{29}$

Este estado é auto-afirmativo em vários sentidos, já que dá a Deusdedit uma sensaçãa de segurança e solidez naquilo que ele entende como função do intelectual e do cientista - são raros os momentos em que ele parece lembrar-se que é advogado. Mesmo sabendo que um tal posicionamento é condenado por alguns autores (Payot, por exemplo), a ele interessa o debate científico e filosólico, a leitura e as oposições e encontros entre Darwin, Rousseau, Herder, Withncy etc. Esse debate, calcado em uma noção de ciência bem definida, ${ }^{30} \mathrm{tem}$ por pressuposto o dever de "fomentar o ensino superior, ministrando-o como

27 MOURA BRASI, Deusdedit. Ontogeniı..., p. 8.

28 Mid...p. 7.

20) Ibid.. p. 7.

30) Seu conceito de ciência é extraído de John Stuart-Mill, e é apresentado como crítica às tentativas de simultancamente trabalhar-se com ciência e religiño: "[...] cm certo campo labora a sciencia desafogadamente, esclarece e decide com segurança e vigor. com sua philosophia, servindo-se dos - methodos de investigações e das condições de prova, indicando uns os meios de chegar a conclusóes; outros o modo de proval-as com exactidio: uns, instrumentos de descobertas, outros de prova [...]". (STUART-MILL, J. A. Comte et le positivisme, p. 55). MOURA BRASIL. Deusdedit. Ontogenia do dircion commercial. Coritiba: Empreza Graphica Paranaense, 1920, p. 27. Em outro momento. cle contrapōe ciência e sensacionalismo literário: "A sciencia tem sua arrogância justificada, sua frieza ante a sensibilidade da rethorica, mesmo moldada pelo genio gaulez." (MOURA BRASIL. Deusdedit. A criminalidade e o analphabetismo. Rèista Acadêmica, Coritiba, v. I. ก. 8, nov. 1917). 
queria Alberto Torres - aos capazes de recebel-o e disseminando a grandeza analônica do Brasil - supino ideal de Sylvio Romero".31

Esta noção de educação transparece também em sua opinião sobre a allabetização, ou a "diffusão dos vinte e cinco util íssimos caracteres, com alguns tragos de moralidade e civismo". Alfabetização essa definida como "Iuz aos trevosos cérebros", çue não deveria ser abrupta ("não tão forte para não maltratar a vista"), nem cm demasia ("moderada, lentamente"), mas apenas suficiente para que lamília e pátria fossem engrandecidas. ${ }^{32}$ Porém ele critica os lugarescomuns que associam a criminalidade com o analfabetismo, em termos principalmente de repetiçōes incontáveis de frases feitas nesse sentido, que Deusdedit considera "asneiras $\mathrm{e}$ infantilidades como [...] [as] bonitas locuções do genial auclor do Legende des siécles, que, se fosse vivo, estaria arrependido de tel-as creado, tal a ingenuidade que cllas contem e o despudor das citações sem termo: 'A ignorancia produz o erro, e o erro produz o crime, Cada escola que se abre, um cárcere se fecha"". Segundo Deusdedit, baseando-se em diversos exemplos de países que começaram a ter ensino obrigatório e nos quais a criminalidade não diminuit, não existe relação alguma entre "gramatica e a moralidade, como não é possível comprehender que uma paixão ou um preconceito de honra, por exemplo, possam ser destruidos pelo Alphabeto".3.3

Em sua luta por não accitar verdades acabadas como a opinião corrente na virada do século sobre o analfabetismo como fonte de crime, Deusdedit combate também a superficialidade com que o seu próprio tempo entende a cultura. Para ele. o "typo moderno", civilizado, que aprende mais por atavismo do que por estudo dedicado é "um pedante, um enfatuado, um tolo, de alma rachitica, carcomida pelo vício", que além de ignorar que sua própria linguagem é composta de jargões típicos "não do povo, mas de funccionario público, soberbo. cezarino", despreza as pessoas simples da população rural. O caipira é o personagem preferido de Deusdedit para catalisar as boas características humanas. ${ }^{34}$

Em conformidade com este espírito, o mais velho dos irmãos Moura Brasil redige vários trabalhos que, além de suas próprias opiniões sobre os temas abordados, traz um elenco de autores que Deusdedit cita, para elogiar ou criticar, e dos quais podemos inferir sobre as formas de leitura que ele realizou desses autores e suas obras.

1917

i) MOURA BRASIL, Deusdedit. Omtogenia.... p. 9.

i2 Id. A criminalidade e o analphabetismo. Revistu Acadêmica. Coritiba, v. 1, n. 8, nov.

3.3 Hid., p. 9.

.34 II.. O exilado. A falua, 1 ago. 1916. 
Seu autor favorito era certamente Clóvis Beviláqua (1859-1944), jurista, político e fillósolo cearense que influenciou toda sua época com seus códigos de dircito e sulas obras críticas. ${ }^{35}$ Os Moura Brasil consultaram a única obra de Bevilácua constante no catálogo da BPPR de 1911, Epochas e individuclidacles, publicala cm 1889. Deusdedit, no entanto, consulta-a apenas em 3 de junho de 1918 (enciuanto Joakim o faz pela primeira vez em julho de 1914 e mais seis veres cntre setembro e outubro de 1914, a intervalos regulares de aproximadamente sele dias, indicando que renovou o empréstimo até fazer a leitura completa da obral).

Sobre Beviláqua, Deusdedit escreve que compartilha "as palavras de meu grande coestadano [...]. Nós os brasileiros somos mais ou menos, em regra geral, autodidactas [...]." ${ }^{36}$ Deusdedit dedica-the um artigo no qual ele questiona as razões da fama e glória serem sempre póstumas. Levado a essas considerações sobre "g̣lórial, justiça e equidade" por pensar em Beviláqua, Deusdedit considera que "O egoismo, a inveja, a despeita ou cousa equivalente faz com que o homem a conceda ao seu merecedor somente quanto este já não deixar desfructar o sabor divino que deve ter a verdadeira gloria, gloria parcial ou universal. É malícia do homem. é invẹja, é injustiça, porque não dizer? é injustiça. Justiça tardia é injustiçil." ir

Bevilácyua aparece, nos escritos de Deusdedit, como um importante orientador do pensamento do advogado e intelectual curitibano. Sua tese de concurso deixal esse débito ainda mais evidente, já que Deusdedit busca demonstrar uma história evolutiva (ou evolucionista) do Direito no Brasil, partindo das ligalçỗes, no passado, entre ciência e religião, anunciando a impossibilidade, em seu presente, dessa relação e historicizando os processos pelos quais ciência (Dircito) e relig̣ião se diferenciam no tempo. A "noção philogenetica do Direito" que serve de leitmotif para a discussão estabelecida por Deusdedit é exatamente um assunto que tanto Clóvis Beviláqua quanto Silvio Romero haviam abordado anteriormente. Nessa conceituação, Deusdedit permite vislumbrar outras influências sobre seu trabalho, como a filosofia afilosótica de Bergson, o positivismo de Comte e o evolucionismo de Spencer, além do pensamento de von Jhering, bastante presente, por sua vez, na obra de Beviláqua. ${ }^{38}$

Nessa construção, Deusdedit elege o pensamento e o trabalho de Bevilácyua como fundador do Direito no Brasil:

35. MEIRA, Silvio. Clóvis Beviláqua: sua vida, sua obra: Fortaleza: EUFC, 1990.

36 MOURA BRASIL, Deusdedit. Ontogenia.... p. 7.

37 Id.. Reddite quae sunt Caesaris Caesari. Revisfa Acadêmica, Coritiba, v. 1, n. 5. p. 121-123. ag0. 1917.

is MEIRA. op. cit., p. 229-248: MOURA BRASIL, Deusdedit. Ontogcriat... p. 20. 
Acredito nas palavras de Clóvis Bevilacqua - nosso orgullho pelo talento, pelo vigor da cultura, pela capacidade immarcessível de intuição e deducçĩo; exemplo fecundo e prolífero de trabalho e amor à pátria, representante supino e inarredavel da consciência jurídica brasileira actual, que nos liberou das vetharias portuguesas e nos tirou do improfícuo arranzel das leis disparatadas. ${ }^{39}$

A caracterização mais completa que Deusdedit fornece de Clóvis Beviláçua é, contudo, feita por oposição a Silvio Romero, como exemplos de intelectuais brasileiros que Deusdedit aprecia em maior e menor grau, respectivamente, cada qual com suas particularidades. Para Deusdedit a personalidade de Beviláqua afigura-se "através de suas obras jurídicas" como um homem "vigoroso, manso, terno". Um erudito e "jurista profundo" que não tem a "intrepidez atrevida, audaciosa e por vez emphatica de Sylvio Romero". A obra de Beviláqua é escrita com "phrase limpida, serena, sem ademanes nem atavios, sem interjeições nem sarcasmo humilhador peculiar a Sylvio Romero, que tanta irritação deve causar ao contendor", mostrando que Deusdedit prefere o texto do primeiro, encuuanto irrita-se, juntamente com o "contendor", com os escritos de Romero. ${ }^{4()}$

Beviláqua, ao contrário de Romero, "não grita, não gesticula ameaçadoramente nem gargalha por debique em vendo a queda do opprimido que é certa". O estilo de argüição de Romero desagrada Dcusdedit por várias razões, pois "Sylvio esphacela, arranca, corta, machuca, sopapo para aqui, sopapo para acolá; e finalmente, victorioso, offegante, delirante - aponta o caminho, rebate o erro, emenda, corrige." Mas o preço desse cstilo é a opressão, que bascia-se no esquecimento dos ensinamentos, no quase ódio e na birra, pois Romero "força [e] quer forçar o vencido -a humilhar-se"." Beviláqua agrada Moura Brasil por ser mais cortês. Ele "não ri, não chacoteia nem se pavoneia do triumpho, tanto rebatendo doutrinas do grande mestre von Jhering, ${ }^{42}$ como esclarecendo o jurista patrio sua falsa compreensão". Beviláqua debatia com

39 MOURA BRASIL, Deusdedit. Ontogenia..., p. 24.

40) Miid., p. 122.

+1 Kid., p. 123

42 As principais influências de Clóvis Beviláqua sĩo Auguste Comte, Stuart-Mill, Émile Littré, Herbert Spencer e Rudolf von Jhering. Este último escreveu A luta pelo Direito e Finalidude do Direino. Beviláqua solicitou e obteve autorização de Jhering para traduzir para o português $A$ hospitalidade do passcalo. De Jhering, Beviláqua retirou seus conceitos evolucionistas, em particular o evolucionismo jurídico. Cl. MEIRA, op. cit., p. 229-248. 
"ternura delicada, feminil". Sempre vitorioso, não tripudiava sobre os adversários, recolhendo-se "ao seu canto, muito quêdo a investigar as sciencias até que um dia novamente, volta com o cajado na mão, não a bater, mas com elle a apontar o caminho ao viajor, como patriarcha gentil que guia a mocidade". 43

Silvio Romero também é um nome recorrente nos artigos e livros de Deusdedit, ainda que muitas vezes, como na comparação entre Romero e Beviláqua, as alusões sejam mais como contraposição que como aceitação das idéias. De Romero, o catálogo da BPPR de 1911 lista apenas seu Ensaio de sociologia (publicado em 1901), porém, os Moura Brasil também consultaram A pátria portuguesa (de 1906) ${ }^{44}$ e a Literatura contemporânea, ${ }^{45}$ acrescidos ao acervo da biblioteca antes das consultas de Joakim e Deusdedit em 1917. Ambos parecem ter tido um súbito interesse pelas obras de Romero, já que as consultaram entre fevereiro e abril daquele ano. Deusdedit solicitou Literatura... em 15 c Pátria... em 22 de fevereiro. Desta data até meados de abril, consultou seguidamente este último livro, com intervalos de sete a dez dias entre as retiradas. Joakim, por sua vez, interessou-se pela Literatura..., que retirou quatro vezes entre 8 e 23 de março. ${ }^{46}$

Contudo, tanto as idéias de Romero quanto as de Beviláqua, com todas as suas matrizes e confrontos, transparecem nas discussões de Deusdedit sobre a oposiçãa ciência-religião, referida acima. A ciência, conceituada rigorosamente, ${ }^{47}$ não pode - ou não pode mais - prender-se a preceitos religiosos. A ciência, sendo evolutiva (como o direito de Beviláqua e a literatura de Romero), aperfeiçoa-se e "comporta exclusivamente verdades prováveis", enquanto a religião "não se objectiva [...] nem ao menos se torna racional, justamente por ser religião". Deusdedit afina-se com Romero ao incluir nessa análise a fase final do pensamento de Auguste Comte, qual seja a da religião

4.3 MOURA BRASIL, Deuscledit. Ontogenia..., p. 123.

44 ROMERO, Silvio. Ensaios de sociologia e literatura. Rio de Janeiro: Garnier, 1901: A pritria portuguesa: o território e a raça. Apreciação do livro de igual título de Té́filo Bragit. Lisboa: Livraria Clássica de A. M. Teixeira, 1906. Apud: CANDIDO, Antonio. O método critico de Sílvio Romero. São Paulo: Edusp, 1988, p. 131.

45 Os livros de retirada não permitem concluir se aqui tratava-se dos Estudos de literatura contemperânea, de 1885, ou dos Novos estudos de literatura contemporânea, de 1898, ou ainda dos Outross estudo de likeratura comemporânea, de 1905.

46. Contudo. eles não consultaram somente estes dois livros nesse mesmo período. De fato, entre 15 de fevereiro e 15 de abril de 1917, Deusdedit e Joakim retiraram outros 11 títulos, como $O$ genio do cristianismo, de Chateaubriand, Anthropologia e Reşas humantas, de Oliveira Martins, As bases da moral, de Domingos Jaguaribe etc., num total de 37 registros de retirada.

47 Ver nota 30 . 
positiva, que como qualquer outra "necessita da fé suprema, da cegueira, por assim dizer, mais suprema, do automatismo". 48

Ao falar sobre a literatura no Brasil, Deusdedit opōe-se novamente a Romero, juntamente com J. Veríssimo, ambos autores de histórias da literatura brasileira, Deusdedit afirma que: "Não dizemos como elle nem tambem como o inquebrantável e aguerrido poeta, jurista e ensaista crítico - philosopho Sylverio [sic] Romero - [que] somos um povo incapaz as carrancudas abstrações philosophicas ou moraes [...], ás artes a todo estudo enfïm que requer perenne, pezadissimas c monasticas meditações." Sua posição é, ao mesmo tempo, próxima e diferente da de Veríssimo e Romero:

Nossa literatura, considerando-a num todo, tão paupérrima e falha, tão vacillante e insegura, atravessa ainda a phase de rebentōes, de embryonez ou de larvas, de esperança apenas renovada, sem chegar ao termo, sem firmeza, prenle de enxertios aberrantes, debil como lyrios brancos a merce das correntes dos ribeiros em dias de enxurrada e ao esfuziar dos ventos esgarridos.

Comtudo, apezar de todos seus defeitos, de toda sua insegurança, a supportar o vendaval de tempo - nossa literatura - podemos falar sem jactancia nem vislumbre de superlatividade orgulhosa, porque peneirando-a algo encontramos plenamente nosso, como semente de espécie nova que se desaggregou das scineaçōes exóticas; apezar dos seus defeitos, dizíamos, ella não é como se desgrenham assanhados e espivitados criticos a la minute, bufarinheiros que adejam lustros e decanos, mirrando a intelligencia e o gosto aproveitaveis em outros mestres, em torno da imprensa $\mathrm{cm}$ vanglorias e irreflectidas e mal pensada conjectura. $^{4+}$

Deusdedit, no intuito de apresentar o Ensaio biographico de seu irmão recém-falecido, estava argumentando em favor do gênio nacional, contido mais em potencial do que na prática. A principal razão dessa espécie de atrofia intelectual, na avaliação de Deusdedit, encontrava-se na importação irrefreada de idćias, desenvolvidas por "sábios exóticos, [que] externaram com bocejos pregruiçosos conclusões obtidas dos calculos obtusos rarefeitos e malfeitos na clausura do gabinete, duvidosos e mareantes quesitos, condenatórios de nossa

48 MOURA BRASIL, Deusdedit. Ontogenia ... p. 28; CANDIDO, O método..., p. 57-78.

4) Id., Ensaio biographico..., Revista Acadêmica, Coritiba, v. 1, n. 4, p. 91 , abr. 1918. 
índole, nossa raça e nossa terra!" que os nacionais "louvaminheiros" bebiam cegamente. ${ }^{50} \mathrm{O}$ exemplo contrário à posição de Veríssimo e Romero é Euclides da Cunha, autor de um grande livro (Os sertões) que estava fadado a "ser ruido pela traça na estante com o sello mal pregado da critica dos analistas do trivial". Como Os sertões, outras obras resultantes de "arrojadas e rarrissimas concepções" tendem a perder-se na "poeira da bibliotheca burguesa ou maniaca" até que a grandeza do livro ou do autor seja novamente sinalizada, antes de retornar novamente "ao silencio carinhoso". É este o quadro que Deusdedit visualiza para o irmão, herói "morto sem vencer" da história literária brasileira. Contudo, as obras de Joakim permaneceram inéditas e seus originais provavelmente estão perdidos, à exceção dos breves trechos publicados. ${ }^{51}$

Os escritos de Deusdedit permitem ainda percebermos incontáveis matrizes intelectuais vigentes nas décadas da virada do século. A verificarmos pelos autores citados em sua tese de concurso, teremos uma lista que inclui, além de Romero e Beviláqua, Darwin, Haeckel, Payot, Rousseau, Withney, Herder, Max-Muller, Pedro Lessa, Alberto Torres, Stuart-Mill, Macaulay e outros. Podemos perceber uma forte preocupação com conceitos advindos da antropologia "a la" Oliveira Martins que servem de justificativa, mais do que explicação, da sociedade em que ele vive. A idéia central em quase todos seus escritos é a do evolucionismo, levado para o campo do darwinismo social, ainda que poucos anos antes este pensamento estivesse próximo a Cesare Lombroso com relação ao determinismo biológico, geográfico e temporal no tocante a questões sociais como a relação entre criminalidade e analfabetismo, ou os meses de nascimento dos gênios.

Deusdedit, como leitor e freqüentador assíduo da BPPR, permite que visualizemos alguns elementos de suas formas de leitura - o que é menos possível no caso de seu irmão mais novo, cuja obra perdeu-se. Resta acessarmos as representações de Deusdedit sobre o objeto físico que contém as idéias expressas em seus próprios escritos, bem como sobre os locais em que os livros são guardados. Além do complexo processo de aprendizado que ele mesmo descreve, representa o próprio livro - como objeto - de formas variadas. A obra humana contida nos livros causa-lhe "pasmo e deslumbramento", ao mesmo tempo que Os sertōes é considerado um livro magistral, destinado "a ser ruído pelas traças" pela superficialidade da crítica. O livro pode também ser, como a

50 MOURA BRASIL, Deusdedit. Ensaio biographico..., Revista Acadêmica, Coritiba, v. 2 , n. 5, p. 125-127, maio 1918.

51 Id. Ensaio biographico..., Revista Acadêmica, Coritiba, v. 2, n. 6, p. 154, jun. 1918; MOURA BRASIL, Joakim, $O$ enfermo... 
Hygiene do amor, de Paolo Mantegazza, "um conselheiro livrinho á mocidade [...] tão sagaz e voluptuoso, as vezes sarcástico e picaresco, mas sincero", 52 quanto pode ser indigno de figurar "num catálogo bibliographico". Já uma biblioteca em que os livros são guardados por puro exibicionismo arrivista é "burguesa ou maníaca", como aquela representada na pequena fábula de 1892:

Ouvio-se grande rumor na bibliotheca de um homem rico. Eram os livros que, aproveitando a ausência do dono, sahiam fora do serio e entabolavam a seguinte palestra:

Um in-quarto, com voz sonora, ainda que fraca:

Confessai, meus amigos, fazemos aqui papel bem triste: nosso proprietário manda de tempos em tempos limpar pelos creados a poeira que nos cobre; porem nunca nos toca, sequer com a ponta dos dedos $[\ldots . .]^{53}$

A própria Biblioteca Pública não escapa de uma análise depreciativa, como aliás era comum no mesmo período. Em 1911, a BPPR, "cuja existência, remontando á 40 annos, é assaz longa e mui dispar com as proporções acanhadas que ainda reveste, [...]" inspira "verdadeira lástima a quem á vista de semelhante abandono, faz ligeiro confronto mental entre ella e as de outros Estados, ricas, reunindo valiosas collecções, diariamente catalogando todas as novidades da litteratura mundial". ${ }^{54} \mathrm{Em} 1920$ ela está:

[...] sem a organização que deveria ter, incompleta, desprezada pelos poderes públicos, sem verbas para o custeio de seu reduzido acervo bibliográphico.

Alojada em lugar inadequado, jogada ao abandono, é frequentada quasi que exclusivamente por alunos inscriptos no estabelecimento em que funciona, sem o conforto e sem os requisitos indispensáveis a semelhante instituição. ${ }^{55}$

52 MOURA BRASIL, Deusdedit. Ensaio biographico..., Revista Acadêmica, Coritiba, v. 2, n. 4, p. 90, abr. 1918 .

53 FILON, A. A bibliotheca. O Futuro, v. 1, n. 11, 20 nov. 1892.

54 BIBLIOTHECA PÚBLICA. O Paraná, Coritiba, v. 6, n. 47, p. 1, 24 abr. 1911.

55 A NOSSA Biblioteca. Gazeta do Povo, 26 ago. 1920, p. 1. 
Para Deusdedit, a Biblioteca Pública não satisfaz seus desejos de conhecimento. Ele, que juntamente com seu irmão a conhecia a fundo, estava familiarizado com seu acervo e sua organização (ou falta dela), considera-a frustrante:

\begin{abstract}
A minguada substancia da nossa desprezada Bibliotheca Pública, a mesquinhez e insufficiencia do elemento que possuimos nos tolhem o passo a fenecer, a esmaecer nossa curiosidade, para muitos problemas interessante[s] como as demographias ou estatisticas de qualquer espécic. ${ }^{56}$
\end{abstract}

Deusdedit, longe de buscar desfazer do local em que buscou boa parte das informações que propiciaram sua formação de advogado e de intelectual, busca o ideal de biblioteca como depósito do conhecimento humano em condições favoráveis de conservação e de consulta, propugnando, como aliás diversos de seus contemporâneos, por bibliotecas públicas as mais completas e dignas possíveis.

Após esse período dos anos de sua formação acadêmica, Deusdedit parece perder seu ímpeto iconoclasta e seu deslumbramento intelectual. Pouco publica na década de 1920, após sua tese de concurso. Talvez funcione como indicador que uma das obras que publica em 1925 seja uma obra religiosa e pia, escrita com sua esposa, onde a ciência é suplantada pela religião. Também como diversos intelectuais de seu tempo, Deusdedit parece ter abraçado o renascimento católico ultramontano e desistido do turbilhão mental envolvido na produção de conhecimento científico e laico. Nesse mesmo período, Deusdedit dá sinais de ter encontrado alguma ocupação no extremo oeste do Estado. Em 1922 ele foi o orador das festas do centenário da independência em Foz do Iguaçu, e cm 1925 publica seu discurso feito naquela ocasião, acompanhado de um soneto chamado "Salve Pátria". Em 1923 ele remete sonetos em castelhano a partir de Posadas, na Argentina, para a revista O Itiberê, de Paranaguá. ${ }^{57} \mathrm{~A}$ partir desse momento, Deusdedit retorna para o aparente ocaso de onde o retiramos.

Embora tênues, essas constatações são resultado da endurance da pesquisa histórica. As leituras de Deusdedit e Joakim perderam-se com seus escritos

56 MOURA BRASIL, Deusdedit. Ensaio biographico..., Revista Acadêmica, Coritiba, v. 2 , n. 4 , p. 90 , abr. 1918.

57 BIBLIOGRAPHIA. O Itiberê, Paranaguá, v. 8, n. 81, p. 15-16, jan. 1926; O ltiberê, Paranaguá, v. 5, n. 51-52, jul./ago. 1923. 
inéditos, mas restou-nos elementos suficientes para tentar reconstruir parte de um mundo intelectual do passado. Um universo pulsante, digladiatório e envolvente salta do material estudado, justificando plenamente o esforço dispendido.

\title{
RESUMO
}

Este texto busca as relações entre a leitura e a escrita em dois personagens da virada do século em Curitiba, tentando compreender nāo só a leitura em si, mas as visões de mundo forjadas através da leitura e veiculadas pela escrita literária ou profissional.

Palavras-chave: história da leitura no Paraná, biblioteca, história da cultura.

\begin{abstract}
This text searches for the relationship between reading and writing in two men of Turn-of-the-Century in Curitiba, trying to understand not only the reading itself, but the ideas of what the world was like, acquired through reading and spread through their own writings, both literary and professional.
\end{abstract}

Key words: history of reading in Paraná, library, history of culture. 